\title{
A conceptual model of barriers and facilitators to primary clinical teams requesting pediatric palliative care consultation based upon a narrative review
}

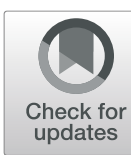

\author{
Jennifer K. Walter ${ }^{*} \mathbb{D}$, Douglas L. Hill, Concetta DiDomenico, Shefali Parikh and Chris Feudtner
}

\begin{abstract}
Background: Despite evidence that referral to pediatric palliative care reduces suffering and improves quality of life for patients and families, many clinicians delay referral until the end of life. The purpose of this article is to provide a conceptual model for why clinical teams delay discussing palliative care with parents.

Discussion: Building on a prior model of parent regoaling and relevant research literature, we argue for a conceptual model of the challenges and facilitators a clinical team might face in shifting from a restorative-focused treatment plan to a plan that includes palliative aspects, resulting in a subspecialty palliative care referral. Like patients and families, clinicians and clinical teams may recognize that a seriously ill patient would benefit from palliative care and shift from a restorative mindset to a palliative approach. We call this transition "clinician regoaling". Clinicians may experience inhibitors and facilitators to this transition at both the individual and team level which influence the clinicians' willingness to consult subspecialty palliative care. The 8 inhibitors to team level regoaling include: 1) team challenges due to hierarchy, 2) avoidance of criticizing colleagues, 3) structural communication challenges, 4) group norms in favor of restorative goals, 5) diffusion of responsibility, 6) inhibited expression of sorrow, 7) lack of social support, 8) reinforcement of labeling and conflict. The 6 facilitators of team regoaling include: 1) processes to build a shared mental model, 2) mutual trust to encourage dissent, 3) anticipating conflict and team problem solving, 4) processes for reevaluation of goals, 5) sharing serious news as a team, 6) team flexibility.
\end{abstract}

Conclusions: Recognizing potential team level inhibitors to transitioning to palliative care can help clinicians develop strategies for making the transition more effectively when appropriate.

Keywords: Pediatric palliative care, Patient care team, Group processes, Communication inhibitors

\section{Background}

Referral to pediatric palliative care reduces suffering and improves the quality of life for these children while providing support to family members $[1,2]$. Despite pediatric palliative care programs becoming more available $[3,4]$, many clinicians do not refer children to palliative or hospice care before they die [5] or refer them only late in the course of the disease, greatly limiting the potential benefits of palliative and hospice services [6].

* Correspondence: walterj1@email.chop.edu

The Children's Hospital of Philadelphia, 2716 South St 11th Floor,

Philadelphia, PA 19146, USA
In this paper we provide a set of reasons why teams may delay consultation, following along with a fictionalized illustrative case.

\section{Methods}

We developed a conceptual model for the team level inhibitors and facilitators of regoaling based upon our clinical experience and social psychology theories of individual and group behavior [7-18]. We then conducted a narrative review of literature in the fields of palliative care, organizational psychology, and social psychology to identify relevant team behaviors around changes in team

(c) The Author(s). 2019 Open Access This article is distributed under the terms of the Creative Commons Attribution 4.0 International License (http://creativecommons.org/licenses/by/4.0/), which permits unrestricted use, distribution, and reproduction in any medium, provided you give appropriate credit to the original author(s) and the source, provide a link to the Creative Commons license, and indicate if changes were made. The Creative Commons Public Domain Dedication waiver (http://creativecommons.org/publicdomain/zero/1.0/) applies to the data made available in this article, unless otherwise stated. 
goals and team function. Searches were conducted in PubMed and PsycINFO for relevant articles.

\section{Discussion \\ REGOALING}

Sara, a healthy toddler, suffered a near drowning accident at a neighbor's pool two days ago. Due to the lack of oxygen, her brain was severely injured. She will never walk or talk again. Despite being overwhelmed by all of her new medical complexity, her parents are hopeful she will still have a good quality of life and want to continue life-sustaining treatments.

For many pediatric conditions, parents and clinicians have a good reason to maintain hope for a cure or return to baseline function, and teams caring for these children describe the importance of supporting parents in hopeful thinking $[19,20]$. Some patients, however, experience a gradual decline of function and quality of life. Our previous research suggests that parents who experience higher levels of negative affect and hopeful thinking (a general belief that one is usually capable of accomplishing goals and generating new goals if some goals are blocked), along with a necessary level of positive affect, are more likely over time to reevaluate their initial restorative seeking goals and replace them with new goals [21]. Based on these findings, we have suggested that parents of seriously ill children can undergo a process of regoaling: disengaging from a set of restorative goals that are no longer attainable or desirable and reengaging in a new set of more attainable goals such as keeping the child comfortable [22]. For regoaling to occur, the clinical team may need to suggest transitioning away from exclusively restorativeseeking treatments to focus on reducing the child's suffering while maintaining quality of life. Referral by the primary clinical team to sub-specialty palliative care may facilitate this regoaling.

We suggest that teams of clinicians must go through a similar process of regoaling for them to consider subspecialty palliative care (Fig. 1 left bottom quadrant). Researchers have done much work to identify inhibitors to initiating palliative care at the individual parent level [21-43], at the family level [24, 27, 44-47] (Fig. 1 right half) and at the individual clinician level [31, 48-55] (Fig. 1 upper left quadrant), but less work has been done on factors that inhibit or facilitate at the team level [24, 56-59] and additional factors that promote or inhibit teams' ability to communicate this recommendation to families [31, 51, 59-62]. Because most care for complex patients happens in interprofessional teams, and the team dynamic substantially influences decisions like consultation with subspecialty palliative care, we have primarily focused on team level factors affecting consultation rather than individual level factors.
The focus of this paper is to explore reasons why teams of clinicians may neglect to either consider initiating palliative care or discussing palliative care with parents.

\section{Individual clinician inhibitors and facilitators to REGOALING}

Individual clinicians may experience several inhibitors to considering palliative care (Fig. 1 upper left quadrant). Many pediatric clinicians lack accurate knowledge of palliative care services or believe that palliative care is primarily for families who have decided to move completely to comfort care $[50,53,55]$. Physicians may perceive that their role is to offer restorative treatment options [49]. Some physicians experience a sense of failure when they are unable to cure patients and report that discussing issues like palliative care and end of life issues with families is difficult [31, 49, 63-66]. When clinicians are uncertain of the patient's prognosis, they may put off goals of care discussions for too long while waiting for more definitive information to provide to families [67-69]. Confirmation bias (a kind of cognitive bias) reduces the likelihood that doctors will question their initial diagnoses and treatment plan [70] and may make them less likely to discontinue a treatment once it has been initiated even if the treatment is no longer effective [71]. Another inhibitor to palliative care referrals may be the personal attachment between clinicians, patients, and family members [69]. Clinicians may worry that they are abandoning the patient if they refer them to palliative care. Many physicians report that breaking bad news and discussing issues like palliative care and end of life issues with families is difficult, stressful, and unsatisfying $[31,63-66]$. This anxiety is worsened by the fact that clinicians acknowledge that they received limited or no communication training in how to share bad news or empathize with an upset parent $[31,48,51,52]$. Clinicians are also under considerable time pressure to see a certain number of patients and families each day which may both increase the cognitive biases mentioned above [72-74], reduce their ability to consider alternative approaches [16], and make them reluctant to initiate difficult conversations about palliative care that may take an unknown amount of time [61, 75, 76]. Each of these factors may increase the likelihood of an individual clinician postponing discussing palliative care with families.

While these individual inhibitors exist, there are also individual level facilitators which support clinician regoaling (Fig. 1 upper left quadrant) like training in primary palliative care $[50,53]$, mindful handling of uncertainty [77, 78], practice of positive coping skills for negative emotions $[79,80]$, as well as communication skills training [81-83].

\section{Team level inhibitors to REGOALING}

5 years later 


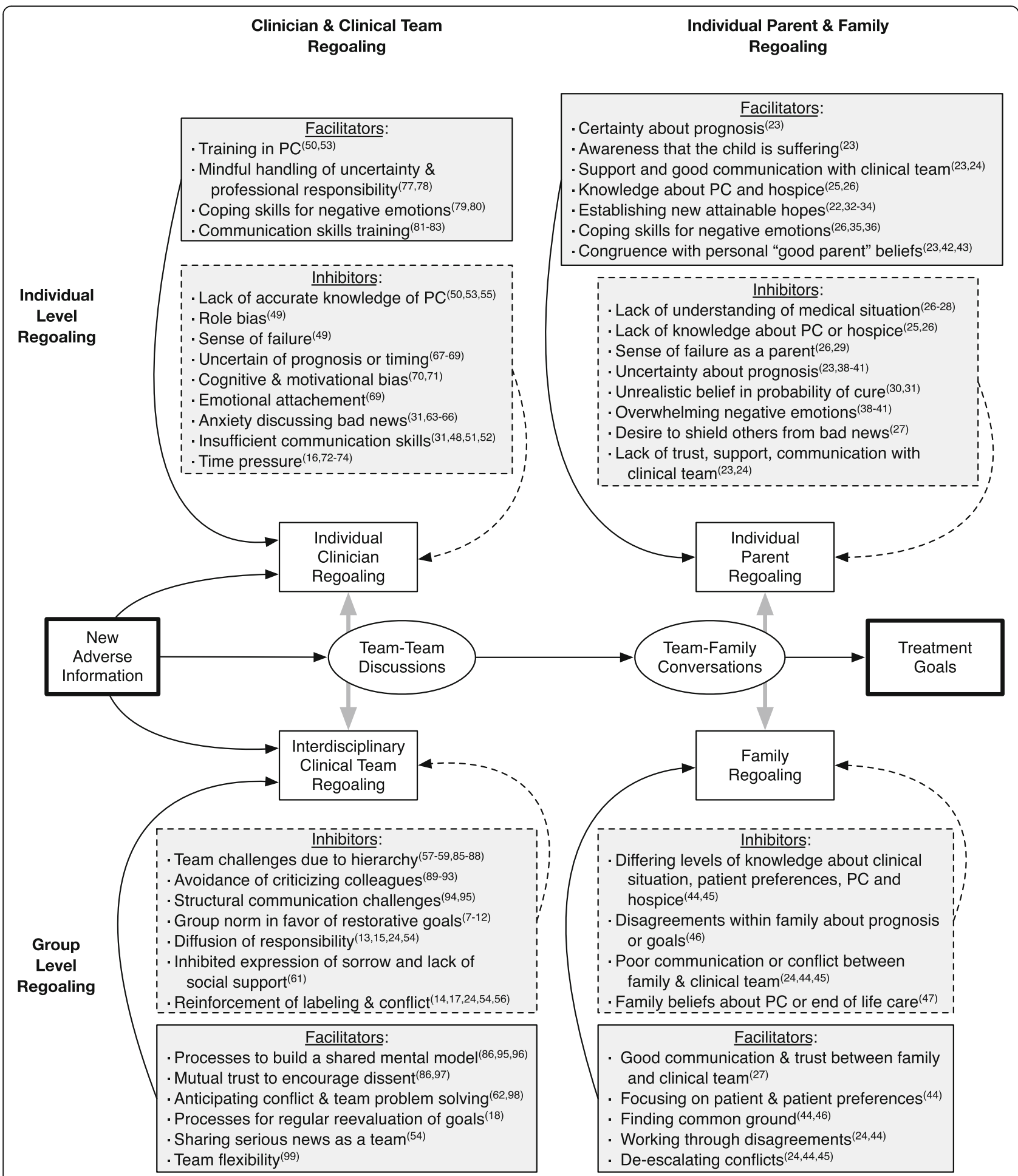

Fig. 1 Conceptual model of facilitators and inhibitors to regoaling and consulting palliative care among individual clinicians, clinical teams, individual parents, and families

The pulmonology social worker, who had followed the family for years, suggested that the medical team consult the palliative care team to support the parents in the tracheostomy decision given her increased frequency and severity of central apneic episodes. The social worker had heard the parents say in previous admissions that they were unsure what the right thing to do was now that Sara kept getting hospitalized. The 
attending pulmonologist and intensivist were reluctant to consult palliative care. To them, the family had indicated they wanted "everything done" to help her over this acute episode and the attendings worried the family would think they were giving up on Sara if they suggested palliative care.

Interprofessional teams are the standard of care for complex patients like children with cancer, or hypoxic brain injury, like Sara [58, 84]. High functioning teams can collaborate in care plan development and execution of patient care. Ideally, each team member contributes their expertise and the overall team engages in a collaborative, iterative decision-making process engaging healthcare professionals, patients, and families [84]. How teams navigate differences in opinion about what to offer families is an important indicator of team function. The following are potential inhibitors that teams may experience in coming to the decision to offer palliative care to a family.

\section{Team communication challenges due to hierarchy}

Team based care can lead to communication breakdowns between clinicians within a given team and between teams of different disciplines (e.g., intensive care and pulmonology) [57-59]. Attendings may fail to discuss with other team members such as nurses or occupational therapists important prognostic information or goals of care conversations that they have had with families [85]. Team members with an inaccurate mental model [86] of the patient's condition are unable to contribute meaningfully to the care plan development, and may feel as though the team thinks their contribution isn't essential. Rigid hierarchical structures may make it difficult for traditionally lower status team members (e.g. nurses and social workers) to share important information with higher status team members (e.g. physicians) [87]. Time pressure can enhance the tendency of a small number of group members to dominate the decisionmaking [88]. The traditional structure of many hospitals where attending physicians come onto a unit for limited periods of time may enhance communication problems if attending physicians do not seek out information from team members who have worked with a family for an extended period of time. In Sara's case, team members perceived the social worker's concerns as less relevant than the attending's experience despite the fact that the social worker had the longest standing relationship with the family.

\section{Avoidance of the perception of criticizing a colleague's decision}

Team members may also avoid challenging the clinical decision-making of their peers $[89,90]$. Clinicians are wary of indicating that their colleagues have made a poor decision, perhaps because of concern that others will judge their decision-making in the future. Clinicians may also worry that their legitimate concerns will be misperceived as a personal attack causing colleagues to react badly [91, 92]. While clinicians report shared norms about not disagreeing with colleagues in front of a patient, many clinicians describe not knowing how to disagree appropriately behind closed doors [93].

\section{Structural challenges to team communication}

Structural factors may worsen teams' abilities to share information and make decisions together. In a study in a neonatal intensive care unit, physicians expressed concern that rounds and meetings did not consistently include all team members [94, 95]. Rounds or interprofessional weekly team meetings may be limited to updates about each patient's current diagnosis and treatment without much open discussion of alternative treatment paths.

Decisions about a potential transition to palliative care may also take place in informal settings outside of the team meetings. These conversations rarely occur with the whole team present either on an inpatient floor or in an outpatient clinic because the relevant clinicians have patient care responsibilities spanning large physical areas. In many instances, clinicians may only engage with a limited number of team members that they feel comfortable with. These teams may miss the perspectives and relevant information from other team members about what the family understands, what the family is worried about, and how the family might respond to the new information and a recommendation of palliative care.

\section{Group norm in favor of restorative-seeking treatment}

Group dynamics can enhance the individual biases in favor of restorative focused treatment. In ambiguous situations, groups can converge on persistent norms based on arbitrary suggestions [7, 8]. Group members may also fail to share new critical information and persist at ineffective strategies when a problem changes $[9,10]$. Cohesive groups in stressful situations may engage in a variety of maladaptive processes also known as "groupthink" (e.g., self-censorship, illusion of unanimity, pressure on dissenters to conform) to reach a decision that ignores contrary evidence [11, 12]. In teams with little mutual trust, dissenters may be reluctant to challenge group norms toward aggressive treatment.

\section{Diffusion of responsibility}

Clinical teams may also experience diffusion of responsibility, when no one individual takes responsibility for doing something to change the situation $[13,15]$. Clinicians may defer that responsibility to another provider who "knows the patient better." Some clinicians may 
strongly believe that cure-seeking treatments are no longer helping the patient, but see it as outside their role to raise such issues [54]. Different team members may convey different direct or implied messages to the family increasing the confusion of the family [24]. Mixed messages and passive disapproval within the team about what is communicated to the family can set the stage for misunderstandings and conflicts between clinicians and families.

\section{Inhibited expression of sorrow/lack of social support}

Often the acknowledgement that a patient has a worsening clinical trajectory and may benefit from subspecialty palliative care will elicit feelings of sorrow among clinicians. However, many clinical teams have group norms about avoiding significant expressions of sorrow, and thus the topics which may elicit them, leading them to avoid discussion at the group level. Clinicians may maintain these norms because of their desire to retain composure professionally as well as their need during the clinical day to continue the fast-paced care of other patients with little to no time allotted to dwelling on these difficult situations [61]. Such norms can make it harder for individual team members to seek support when coping with negative emotions and may increase the risk for depression and burnout among clinicians. These norms of behavior are often ingrained early in training and individuals who are too emotional receive implicit and explicit messages that they need to learn to "cope" differently.

\section{Labeling parents and escalating conflict}

Some clinicians report that the main inhibitor to initiating difficult goals of care discussions is that the patients and family were not "ready." [54] This perception may be the result of parents having responded in the past to difficult news with anger or an insistent request for more treatment. Clinicians may treat these reactions as fixed, unchangeable traits of the family, instead of recognizing that many families undergo a gradual transition from one set of goals to another [22]. When teams develop negative beliefs about a person, whether based on stereotypes or past experience, these beliefs may become self-fulfilling prophecies, especially if an individual is expected to be hostile $[14,17]$.

Clinical teams who see family members a problem to be overcome may end up rigidly adhering to their position and issuing ultimatums to the family [56]. Conflicts can escalate from mild cases of insensitive communication to severe cases where the conflict between clinicians and parents becomes the central focus instead of the child [24].

\section{Facilitators of team REGOALING}

2 years further along

Sara, having received her tracheostomy, has required more frequent hospitalizations. At her next hospitalization, the primary intensivist agreed to call a team meeting to discuss her gradual decline. The social worker had engaged her parents in conversations about preliminary goals of care and thought they would benefit from learning about out of hospital donot-resuscitate orders and even possibly enrolling in hospice. Sara's neurologist worried that her family would get the wrong impression if palliative care was mentioned. He worried that the team was giving them an unintended message that the medical team had given up. The palliative care team met with John and Maria and learned that they were increasingly worried about Sara's suffering and feared she would die in the hospital when they weren't there. Her family was not ready to sign a physician's order for life sustaining treatment (POLST) form or enroll in hospice, but they made a plan to see the palliative care team at their next outpatient pulmonary visit. The parents said they appreciated the support from the palliative care team and they were relieved to finally be able to talk about some of their fears.

There are a number of strategies that can help teams work together and to consider palliative care before patients are close to death. These include: a) building and maintaining a shared model of the situation, b) increasing mutual trust and constructive dissent, c) anticipating potential conflicts with families and working as a team to problem solve them, d) making sure to regularly reevaluate goals as a team, e) working together as a team to break bad news, and f) recognizing the importance of team flexibility.

\section{Processes to build a shared mental model}

Clinical teams need to have a shared mental model of a patient's current disease trajectory and the family's goals in order to develop an appropriate care plan. Like Sara's neurologists who needed to be updated on the shift in her trajectory, care teams often need to revisit central information to establish a shared mental model. Team leaders can encourage all team members to attend and participate in meetings and rounds, and make sure that team members clearly present key information for each patient [96].

Team leaders can also put processes in place to review relevant changes as a group to ensure that all team members know about changes in patient's situation. This may mean team members repeat central information multiple times to team members on different shifts 
through a structured format of communication. Team members who have continuity with patients across multiple attendings, like social workers, can also play an important role in sharing important information about the family with all team members. Team leaders can also reduce the danger of mixed messages by encouraging subspecialists to review treatment recommendations with the attending physician before speaking directly with the family. Pre-meetings before a family meeting provide an excellent opportunity for developing a shared mental model and reviewing the care plan options.

Sharing information helps clinicians make the transition to palliative care goals because clinicians need information in two key areas: how much the patient's condition has declined over time and whether the family is ready to consider palliative care. Some patients may go through a sudden change (for better or worse) that significantly impacts the appropriateness of cure-seeking treatment and long-term quality of life. In some cases, a clinician may think that a parent is not ready to discuss palliative care based on one conversation, and be unaware that the parent has expressed a change in attitudes to another team member.

\section{Mutual trust to encourage constructive dissent}

Studies have found that clear shared goals has enhanced effective team work in many settings, including healthcare [86]. Some clinical teams may have a shared goal of providing restorative or cure-directed treatments. However, when these treatments prove to be ineffective, the team may need to reaffirm the goal of providing care consistent with a patient and parent's goals and values. In addition, team members need to have sufficient trust that each team member is contributing in their own way toward that goal. Groups will tolerate higher levels of conflict and debate if the members feel that they are working together to solve a problem [97].

Clinical teams (and team leaders) should encourage constructive dissent in discussions of treatment options for seriously ill patients encouraging members of the team to speak up about the possibility of initiating palliative care. If the team is biased toward believing that palliative care is only relevant in the very last stage of life, team members can offer the opposing view of what palliative care can offer families earlier in their disease course. Ideally a palliative care representative would attend regular team meetings providing an alternative perspective for what a patient's care plan could include. Alternatively, teams can have a process where members deliberately provide a devil's advocate perspective, posing negatively framed question like, "why wouldn't we consider palliative care for this patient?" to help the team reevaluate whether the current treatment plan is appropriate.

\section{Anticipating conflict with families and team problem- solving}

Teams should attempt to be aware of conflicts between clinicians and families and develop plans to address the conflict rather than avoiding it [62]. For example, if one team member describes a family as "difficult", the other team member can ask for more information. In what way are they difficult? What seems to trigger conflicts with this family? What are they most concerned about? What can we do differently to handle this situation? Meetings prior to a family meeting provide opportunities to review previous conflicts, develop consistent team language acknowledging the challenges families have faced, and make explicit the team's commitment to improving care and communication moving forward [98].

\section{Processes for regular reevaluation of goals}

For seriously ill patients, clinicians may benefit from periodically stepping back and adopting a deliberative mindset to think about the big picture and reevaluate the pros and cons of the patient's current treatment goals [18]. What was the patient's previous baseline? Does the treatment have a meaningful chance of helping the patient? Will the current treatment approach reduce the patient's quality of life? Are there distressing symptoms that would benefit from palliative care? What are the family members hoping for? Instituting a continuity physician who can pose these questions or establishing a team process to raise these questions for patients who meet a threshold for palliative care may facilitate the consideration of whether subspecialty palliative care is warranted. Having group consensus that this conversation about palliative care should be discussed can be empowering for members of the team lower on the hierarchy who may perceive a value to palliative care consultation, but are reluctant to challenge those in leadership.

\section{Sharing serious news as a team}

Clinical teams can also work together to establish norms for breaking serious news to families. One study of goals of care discussions with family members of adult patients found that nurses, residents, and physicians thought physicians were the most appropriate team member to initiate discussions of these difficult topics but other team members could also play a role in these discussions [54]. Prior to the family meeting, team members can identify important roles to be fulfilled to ensure that they coordinate with each other during the meeting and do not overlook any important tasks. A "facilitator" for the meeting will keep the meeting on track and consistently check in with the family. An "information giver" will provide relevant medical information, while a "emotional support person" will track the patient and 
family's emotion to ensure that is responded to in an empathetic way. Finally, a "recorder" will keep track of relevant information to be shared in the medical record and with the family at the end of the meeting.

\section{Importance of team flexibility}

Effective teams also need to quickly recognize when a situation has changed, communicate about the change, and adapt their response appropriately [99]. An effective clinical team can be compared to a jazz band. Musicians in a jazz band need to have both the individual ability to play an instrument and the ability and flexibility to respond to what the rest of the band is doing. A jazz musician may be an excellent soloist, but will have trouble playing with a band without these collaboration skills. An individual clinician with excellent communication skills may still confuse or upset a family if the clinician delivers a message that doesn't fit with what others on the team have said. When team members are aware of each member's role and responsibilities, they can ensure that all essential tasks are covered and fill in for each other even when an individual team member is overloaded or unavailable.

In some cases, a parent may develop a close rapport with a team member who is not a physician or high in the traditional medical hierarchy. A flexible, collaborative team will be able to follow up on the parent's concerns even if the trusted team member is not the one who usually initiates palliative care discussions. Collaboration can also play an important role in successful team meetings. One team member may recognize that a parent is confused or overwhelmed and redirect the meeting to address this. A flexible team will follow that cue.

In Fig. 1, on the right hand side, we have distilled previous research on the inhibitors and facilitators of parent/family level regoaling [21-23, 34] with the newly described individual clinician/team level aspects of regoaling represented on the left. By demonstrating the interaction between individual experiences of regoaling for both clinicians and parents with other team members and family members as parallel and conjoined processes, we hope to show the complexity of factors that need to align for a successful involvement of sub-specialty palliative care teams. Individual clinicians' experience of regoaling is impacted by team-team discussions just as parental regoaling is impacted by discussions with other family members. The articulation of which inhibitor may be causing either the team or family to decline palliative care involvement allows for more targeted strategies to mitigate those inhibitors. Future research can explore the ways that teams and families may respond to facilitators in light of confounding inhibitors for accepting subspecialty palliative care consultation.

\section{Conclusion}

Delayed palliative care referrals for dying children often lead to increased suffering for both the children and their families. Even clinicians who recognize the value that palliative care offers patients and families, and who are frustrated by delays in initiating palliative care, may have trouble initiating the transition. Recognizing potential inhibitors to transitioning to palliative care at the individual and the team level can help clinicians develop individual and team strategies for making the transition to palliative care more effectivity when appropriate. Such strategies can improve the quality of life for these patients and their families.

Acknowledgments

Not applicable.

Authors' contributions

JW contributed to the design of the study, literature review and was a major contributor in writing of the manuscript, DH contributed to the design of the study, literature review and was a major contributor in writing of the manuscript, CD contributed to the design of the study and substantially edited the work, SP contributed to the design of the study and substantially edited the work, and CF contributed to the design of the study and substantially edited the work. All authors read and approved the final manuscript.

\section{Funding}

Funding for this project was provided by the National Cancer Institute Grant R21CA198049-02 and contributed to the design of the study, analysis and interpretation of data and in writing the manuscript. Dr. Walter also received funding from the National Heart, Lung, And Blood Institute of the National Institutes of Health under Award Number K23HL141700 for the writing of the manuscript. The content is solely the responsibility of the authors and does not necessarily represent the official views of the National Institutes of Health.

Availability of data and materials

Data sharing is not applicable to this article as no datasets were generated or analysed during the current study.

Ethics approval and consent to participate

No unpublished human subjects data was used in this debate piece.

Consent for publication

Not applicable.

Competing interests

The authors declare that they have no competing interests.

Received: 15 July 2019 Accepted: 9 December 2019

Published online: 21 December 2019

\section{References}

1. Gans D, Kominski GF, Roby DH, Diamant AL, Chen X, Lin W, et al. Better outcomes, lower costs: palliative care program reduces stress, costs of care for children with life-threatening conditions. Policy Brief UCLA Cent Health Policy Res. 2012;(PB2012-3):1-8.

2. Mack JW, Wolfe J. Early integration of pediatric palliative care: for some children, palliative care starts at diagnosis. Curr Opin Pediatr. 2006;18(1):10-4.

3. NHPCO Facts and Figures: Hospice Care in America. Alexandria, VA: National Hospice and Palliative Care Organization; 2014

4. Institute of Medicine. Dying in America: Improving quality and honoring individual preferences near the end of life. Washington, DC: The National Academies Press; 2015. 
5. Mack JW, Chen LH, Cannavale K, Sattayapiwat O, Cooper RM, Chao CT. Endof-Life Care Intensity Among Adolescent and Young Adult Patients With Cancer in Kaiser Permanente Southern California. JAMA Oncol. 2015.

6. Zhukovsky D, Herzog C, Kaur G, Palmer JL, Bruera E. The impact of palliative care consultation on symptom assessment, communication needs, and palliative interventions in pediatric patients with cancer. J Palliat Med. 2009;12(4):343-9.

7. Sherif M. An experimental approach to the study of attitudes. Sociometry. 1937;1:90-8

8. MacNeil MK, Sherif M. Norm change over subject generations as a function of arbitrariness of prescribed norms. J Pers Soc Psychol. 1976;34(5):762-73.

9. Kelly JR, Karau SJ. Group decision making: The effects of initial preferences and time pressure. Pers Soc Psychol Bull. 1999;25(11):1342-54

10. LePine JA. Adaptation of teams in response to unforeseen change: effects of goal difficulty and team composition in terms of cognitive ability and goal orientation. J Appl Psychol. 2005;90(6):1153-67.

11. Janis IL. Victims of groupthink: A psychological study of foreign-policy decisions and fiascoes: Houghton Mifflin, Oxford; 1972.

12. Janis IL. Group Think, 2nd Edition. Boston, MA: Houghton Mifflin Company; 1982.

13. Darley JM, Latane B. Bystander intervention in emergencies: Diffusion of responsibility. J Pers Soc Psychol. 1968;8(4, Pt.1):377-83.

14. Darley JM, Fazio RH. Expectancy confirmation processes arising in the social interaction sequence. Am Psychol. 1980;35(10):867-81.

15. Fischer P, Krueger Jl, Greitemeyer T, Vogrincic C, Kastenmuller A, Frey D, et al. The bystander-effect: A meta-analytic review on bystander intervention in dangerous and non-dangerous emergencies. Psychol Bull. 2011;137(4):517-37.

16. Richter $L$, Kruglanski AW. Seizing on the latest: Motivationally driven recency effects in impression formation. J Exp Soc Psychol. 1998:34(4):313-29.

17. Madon S, Jussim L, Guyll M, Nofziger H, Salib ER, Willard J, et al. The accumulation of stereotype-based self-fulfilling prophecies. J Pers Soc Psychol. 2018;115(5):825-44.

18. Brandstatter $V$, Frank $E$. Effects of deliberative and implemental mindsets on persistence in goal-directed behavior. Pers Soc Psychol Bull. 2002;28(10):1366-78

19. Barrera M, Granek L, Shaheed J, Nicholas D, Beaune L, D'Agostino NM, et al. The tenacity and tenuousness of hope: parental experiences of hope when their child has a poor cancer prognosis. Cancer Nurs. 2013;36(5):408-16.

20. Kylma J, Juvakka T. Hope in parents of adolescents with cancer-factors endangering and engendering parental hope. Eur J Oncol Nurs. 2007;11(3):262-71.

21. Feudtner C, Carroll KW, Hexem KR, Silberman J, Kang TI, Kazak AE. Parental hopeful patterns of thinking, emotions, and pediatric palliative care decision making: a prospective cohort study. Arch Pediatr Adolesc Med. 2010;164(9):831-9

22. Hill DL, Miller V, Walter JK, Carroll KW, Morrison WE, Munson DA, et al. Regoaling: a conceptual model of how parents of children with serious illness change medical care goals. BMC Palliat Care. 2014;13(1):9.

23. Kars MC, Grypdonck MH, Beishuizen A. Meijer-van den Bergh EM, van Delden JJ. Factors influencing parental readiness to let their child with cancer die. Pediatr Blood Cancer. 2010;54(7):1000-8.

24. Forbat $L$, Teuten B, Barclay S. Conflict escalation in paediatric services: findings from a qualitative study. Arch Dis Child. 2015;100(8):769-73.

25. Ranallo L. Improving the Quality of End-of-Life Care in Pediatric Oncology Patients Through the Early Implementation of Palliative Care. J Pediatr Oncol Nurs. 2017:34(6):374-80.

26. Majesko A, Hong SH, Weissfeld L, White DB. Identifying family members who may struggle in the role of surrogate decision maker. Crit Care Med. 2012:40(8):2281-6.

27. Marsac ML, Kindler C, Weiss D, Ragsdale L. Let's Talk About It: Supporting Family Communication during End-of-Life Care of Pediatric Patients. J Palliat Med. 2018;21(6):862-78.

28. Wolfe J, Klar N, Grier HE, Duncan J, Salem-Schatz S, Emanuel EJ, et al. Understanding of prognosis among parents of children who died of cancer: impact on treatment goals and integration of palliative care. JAMA. 2000; 284(19):2469-75.

29. Maurer SH, Hinds PS, Spunt SL, Furman WL, Kane JR, Baker JN. Decision making by parents of children with incurable cancer who opt for enrollment on a phase I trial compared with choosing a do not resuscitate/ terminal care option. J Clin Oncol. 2010;28(20):3292-8.
30. Mack JW, Cook EF, Wolfe J, Grier HE, Cleary PD, Weeks JC. Understanding of prognosis among parents of children with cancer: parental optimism and the parent-physician interaction. J Clin Oncol. 2007;25(11):1357-62.

31. Durall A, Zurakowski D, Wolfe J. Barriers to Conducting Advance Care Discussions for Children With Life-Threatening Conditions. Pediatrics. 2012; 129(4):e975-82.

32. Feudtner C. Hope and the prospects of healing at the end of life. J Altern Complement Med (New York, NY). 2005;11 Suppl 1:S23-\$30.

33. Feudtner C. The breadth of hopes. N Engl J Med. 2009;361(24):2306-7.

34. Granek L, Barrera M, Shaheed J, Nicholas D, Beaune L, D'Agostino N, et al. Trajectory of parental hope when a child has difficult-to-treat cancer: a prospective qualitative study. Psychooncology. 2013;22(11):2436-44.

35. Vig EK, Starks H, Taylor JS, Hopley EK, Fryer-Edwards K. Surviving surrogate decision-making: what helps and hampers the experience of making medical decisions for others. J Gen Intern Med. 2007;22(9):1274-9.

36. Iverson E, Celious A, Kennedy CR, Shehane E, Eastman A, Warren V, et al. Factors affecting stress experienced by surrogate decision makers for critically ill patients: implications for nursing practice. Intensive Crit Care Nurs. 2014;30(2):77-85.

37. Hill DL, Nathanson PG, Fenderson RM, Carroll KW, Feudtner C. Parental Concordance Regarding Problems and Hopes for Seriously III Children: A Two-Year Cohort Study. J Pain Symptom Manage. 2017;53(5):911-8.

38. Chambers-Evans J, Carnevale FA. Dawning of awareness: the experience of surrogate decision making at the end of life. J Clin Ethics. 2005;16(1):28-45.

39. Radwany S, Albanese T, Clough L, Sims L, Mason H, Jahangiri S. End-of-life decision making and emotional burden: placing family meetings in context. Am J Hosp Palliat Care. 2009;26(5):376-83.

40. Tilden VP, Tolle SW, Nelson CA, Fields J. Family decision-making to withdraw life-sustaining treatments from hospitalized patients. Nurs Res. 2001;50(2):105-15.

41. Wendler D, Rid A. Systematic review: the effect on surrogates of making treatment decisions for others. Ann Intern Med. 2011;154(5):336-46.

42. Hinds PS, Oakes LL, Hicks J, Powell B, Srivastava DK, Spunt SL, et al. "Trying to be a good parent" as defined by interviews with parents who made phase I, terminal care, and resuscitation decisions for their children. J Clin Oncol. 2009;27(35):5979-85.

43. Feudtner C, Walter JK, Faerber JA, Hill DL, Carroll KW, Mollen CJ, et al. Goodparent beliefs of parents of seriously ill children. JAMA Pediatr. 2015;169(1):39-47.

44. Eves MM, Esplin BS. "She Just Doesn't Know Him Like We Do": Illuminating Complexities in Surrogate Decision Making. J Clin Ethics. 2015;26(4):350-4.

45. Su CT, McMahan RD, Williams BA, Sharma RK, Sudore RL. Family matters: effects of birth order, culture, and family dynamics on surrogate decisionmaking. J Am Geriatr Soc. 2014;62(1):175-82.

46. Edwards KE, Neville BA, Cook EF Jr, Aldridge SH, Dussel V, Wolfe J. Understanding of prognosis and goals of care among couples whose child died of cancer. J Clin Oncol. 2008;26(8):1310-5.

47. Braun UK, Beyth Rj Fau - Ford ME, Ford Me Fau - McCullough LB, McCullough LB. Voices of African American, Caucasian, and Hispanic surrogates on the burdens of end-of-life decision making. J Gen Intern Med. 2008;23(3):1525-497.

48. Contro N, Larson J, Scofield S, Sourkes B, Cohen HJ. Hospital staff and family perspectives regarding quality of pediatric palliative care. Pediatr. 2004:114:1248-52.

49. Jackson VA, Mack J, Matsuyama R, Lakoma MD, Sullivan AM, Arnold RM, et al. A qualitative study of oncologists' approaches to end-of-life care. J Palliat Med. 2008;11(6):893-906.

50. McCabe ME, Hunt EA, Serwint JR. Pediatric residents' clinical and educational experiences with end-of-life care. Pediatr. 2008;121(4):e731-7.

51. Michelson KN, Ryan AD, Jovanovic B, Frader J. Pediatric residents' and fellows' perspectives on palliative care education. J Palliat Med. 2009;12(5):451-7.

52. Roth M, Wang D, Kim M, Moody K. An assessment of the current state of palliative care education in pediatric hematology/oncology fellowship training. Pediatr Blood Cancer. 2009:53(4):647-51.

53. Thompson LA, Knapp C, Madden V, Shenkman E. Pediatricians' perceptions of and preferred timing for pediatric palliative care. Pediatr. 2009;123(5):e777-82.

54. You JJ, Downar J, Fowler RA, Lamontagne F, Ma IW, Jayaraman D, et al. Barriers to goals of care discussions with seriously ill hospitalized patients 
and their families: a multicenter survey of clinicians. JAMA Intern Med. 2015;175(4):549-56.

55. Bogetz JF, Root MC, Purser L, Torkildson C. Comparing Health Care ProviderPerceived Barriers to Pediatric Palliative Care Fifteen Years Ago and Today. J Palliat Med. 2019;22(2):145-51.

56. Back AL. Working to Shift Clinician Perception. JAMA Intern Med. 2015; 175(9):1577-8.

57. Heinze KE, Nolan MT. Parental Decision Making for Children With Cancer at the End of Life: A Meta-Ethnography. J Pediatr Oncol Nurs. 2012;29(6):337-45.

58. Penson RT, Kyriakou H, Zuckerman D, Chabner BA, Lynch TJ. Teams: Communication in Multidisciplinary Care. Oncologist. 2006;11(5):520-6

59. Prouty C, Mazor K, Greene S, Roblin D, Firneno C, Lemay C, et al. Provider's Perceptions of Communication Breakdowns in Cancer Care. J Gen Intern Med. 2014:1-9.

60. Hill DL, Walter JK, Casas JA, DiDomenico C, Szymczak JE, Feudtner C. The codesign of an interdisciplinary team-based intervention regarding initiating palliative care in pediatric oncology. Support Care Cancer. 2018;26(9):3249-56.

61. Szymczak JE, Schall T, Hill DL, Walter JK, Parikh S, DiDomenico C, et al. Pediatric Oncology Providers' Perceptions of a Palliative Care Service: The Influence of Emotional Esteem and Emotional Labor. J Pain Symptom Manage. 2018;55(5):1260-8.

62. Back AL, Arnold RM. Dealing with conflict in caring for the seriously ill: "it was just out of the question". JAMA. 2005;293(11):1374-81.

63. Hancock K, Clayton JM, Parker SM, Wal der S, Butow PN, Carrick S, et al. Truth-telling in discussing prognosis in advanced life-limiting illnesses: a systematic review. Palliat Med. 2007;21(6):507-17.

64. Anselm AH, Palda V, Guest CB, McLean RF, Vachon MLS, Kelner M, et al. Barriers to communication regarding end-of-life care: perspectives of care providers. J Crit Care. 2005;20(3):214-23.

65. Granek L, Krzyzanowska MK, Tozer R, Mazzotta P. Oncologists' strategies and barriers to effective communication about the end of life. J Oncol Pract. 2013;9(4):e129-35.

66. Foley KM, H G. Improving Palliative Care for Cancer. Washington, DC: National Academies Press; 2001.

67. Smith AK, White DB, Arnold RM. Uncertainty: the other side of prognosis. N Engl J Med. 2013;368(26):2448.

68. Davies B, Sehring SA, Partridge JC, Cooper BA, Hughes A, Philp JC, et al. Barriers to Palliative Care for Children: Perceptions of Pediatric Health Care Providers. Pediatr. 2008;121(2):282-8.

69. Hill DL, Walter JK, Szymczak JE, DiDomenico C, Parikh S, Feudtner C. Seven Types of Uncertainty When Clinicians Care for Pediatric Patients With Advanced Cancer. J Pain Symptom Manage. 2019.

70. Klein JG. Five pitfalls in decisions about diagnosis and prescribing. BMJ. 2005;330(7494):781-3.

71. Aberegg SK, Haponik EF, Terry PB. Omission bias and decision making in pulmonary and critical care medicine. Chest. 2005;128(3):1497-505.

72. Moon J, Anderson JR. Timing in multitasking: Memory contamination and time pressure bias. Cogn Psychol. 2013;67(1-2):26-54

73. Palada H, Neal A, Tay R, Heathcote A. Understanding the causes of adapting, and failing to adapt, to time pressure in a complex multistimulus environment. J Exp Psychol. 2018;24(3):380-99.

74. Ogdie AR, Reilly JB, Pang WG, Keddem S, Barg FK, Von Feldt JM, et al. Seen through their eyes: Residents' reflections on the cognitive and contextual components of diagnostic errors in medicine. Acad Med. 2012;87(10):1361-7.

75. Midtbust MH, Alnes RE, Gjengedal E, Lykkeslet E. Perceived barriers and facilitators in providing palliative care for people with severe dementia: the healthcare professionals' experiences. BMC Health Serv Res. 2018;18(1):709.

76. Visser M, Deliens L, Houttekier D. Physician-related barriers to communication and patient- and family-centred decision-making towards the end of life in intensive care: a systematic review. Crit Care (London, England). 2014;18(6):604.

77. Fortney L, Luchterhand C, Zakletskaia L, Zgierska A, Rakel D. Abbreviated mindfulness intervention for job satisfaction, quality of life, and compassion in primary care clinicians: A pilot study. Ann Fam Med. 2013;11(5):412-20.

78. Goodman MJ, Schorling JB. A mindfulness course decreases burnout and improves well-being among healthcare providers. Int J Psychiatry Med. 2012:43(2):119-28.

79. Magtibay DL, Chesak SS, Coughlin K, Sood A. Decreasing Stress and Burnout in Nurses. JONA. 2017;47(7/8):391-5.

80. West CP, Dyrbye LN, Rabatin JT, Call TG, Davidson JH, Multari A, et al. Intervention to promote physician well-being, job satisfaction, and professionalism: a randomized clinical trial. JAMA Intern Med. 2014;174(4):527-33.

81. Arnold RM, Back AL, Barnato AE, Prendergast TJ, Emlet LL, Karpov I, et al. The Critical Care Communication project: improving fellows' communication skills. J Crit Care. 2015;30(2):250-4.

82. Back AL, Arnold RM, Baile WF, Fryer-Edwards KA, Alexander SC, Barley GE, et al. Efficacy of communication skills training for giving bad news and discussing transitions to palliative care. Arch Intern Med. 2007;167(5):453.

83. Curtis JR, Ciechanowski PS, Downey L, Gold J, Nielsen EL, Shannon SE, et al. Development and evaluation of an interprofessional communication intervention to improve family outcomes in the ICU. Contemp Clin Trials. 2012.

84. Menard C, Merckaert I, Razavi D, Libert Y. Decision-making in oncology: a selected literature review and some recommendations for the future. Curr Opin Oncol. 2012;24(4):381-90.

85. Bail K, Morrison P. Interprofessional communication of prognosis: teaching to bridge the gaps. Educ Health (Abingdon). 2011;24(1):326.

86. Baker DP, Day R, Salas E. Teamwork as an essential component of highreliability organizations. Health Serv Res. 2006;41(4 Pt 2):1576-98.

87. Nembhard IM, Edmondson AC. Making it safe: The effects of leader inclusiveness and professional status on psychological safety and improvement efforts in health care teams. J Org Behav. 2006;27(7):941-66.

88. Pierro A, Mannetti L, De Grada E, Livi S, Kruglanski AW. Autocracy bias in informal groups under need for closure. Pers Soc Psychol Bull. 2003;29(3):405-17.

89. Leape LL, Shore MF, Dienstag JL, Mayer RJ, Edgman-Levitan S, Meyer GS, et al. Perspective: a culture of respect, part 1: the nature and causes of disrespectful behavior by physicians. Acad Med. 2012;87(7):845-52.

90. McDaniel SH, Morse DS, Reis S, Edwardsen EA, Gurnsey MG, Taupin A, et al. Physicians criticizing physicians to patients. J Gen Intern Med. 2013;28(11):1405-9.

91. Casarett DJ. When doctors disagree. Virtual Mentor. 2006;8(9):571-6.

92. When doctors disagree. J Med Ethics. 1979;5(2):86-8.

93. Leape LL, Shore MF, Dienstag JL, Mayer RJ, Edgman-Levitan S, Meyer GS, et al. Perspective: a culture of respect, part 2: creating a culture of respect. Acad Med. 2012;87(7):853-8.

94. Thomas EJ, Sherwood GD, Mulhollem JL, Sexton JB, Helmreich RL. Working together in the neonatal intensive care unit: provider perspectives. J Perinatol. 2004;24(9):552-9.

95. Lamb BW, Sevdalis N, Arora S, Pinto A, Vincent C, Green JS. Teamwork and team decision-making at multidisciplinary cancer conferences: barriers, facilitators, and opportunities for improvement. World J Surg. 2011;35(9):1970-6.

96. Lamb B, Sevdalis N, Benn J, Vincent C, Green J. Multidisciplinary cancer team meeting structure and treatment decisions: a prospective correlational study. Ann Surg Oncol. 2013;20(3):715-22.

97. Huang J-C. Unbundling task conflict and relationship conflict: The moderating role of team goal orientation and conflict management. Int J Confl Manag. 2010;21(3):334-55.

98. Walter JK, Arnold RM, Curley MAQ, Feudtner C. Teamwork when Conducting Family Meetings: Concepts, Terminology, and the Importance of Team-Team Practices. J Pain Symptom Manage. 2019.

99. Thomas EJ, Sexton JB, Helmreich RL. Translating teamwork behaviours from aviation to healthcare: development of behavioural markers for neonatal resuscitation. Qual Saf Health Care. 2004;13(Suppl 1):i57-64.

\section{Publisher's Note}

Springer Nature remains neutral with regard to jurisdictional claims in published maps and institutional affiliations.

\section{Ready to submit your research? Choose BMC and benefit from:}

- fast, convenient online submission

- thorough peer review by experienced researchers in your field

- rapid publication on acceptance

- support for research data, including large and complex data types

- gold Open Access which fosters wider collaboration and increased citations

- maximum visibility for your research: over $100 \mathrm{M}$ website views per year

At $\mathrm{BMC}$, research is always in progress.

Learn more biomedcentral.com/submissions 